\section{Commentary: Aging, cognitive decline and performance: Will prevention provide the cure?}

\author{
J. W. Awori Hayanga, MD, MPH, MHL, FACS, FRCS, \\ FCCP, and Alper Toker, MD
}

In the current issue, Rosengart ${ }^{1}$ explores the effect of cognition and age on human performance and the contribution of cognitive errors in deficiencies in performance are specifically examined. The adjudication of errors in the clinical environment represents a timely initiative in the quest for excellence and the establishment of quality standards in certification and credentialing realms. The author explicitly addresses the simultaneous contribution of aging to the spectrum of performance and deficits therein. This is pertinent as a growing proportion of cardiothoracic surgeons is approaching retirement in an era of intense scrutiny and sometimes relentless judgement. ${ }^{2,3}$ The interface of age and experience is complex and not easily explained through the lens alone. Categorizing age in absolute terms, nevertheless, necessitates defining what is meant by "young," "elderly," "aging," and "aged." Age proffers experience and experience affords judgement and although age is accumulated in predictable increments, experience is not. Instead, experience is garnered in bursts and fits and starts. Discounting the wisdom borne from age might conjure conclusions on the basis of too narrow a lens of opinion. Age and outcome likely share an inverted V-shaped relationship rather than a linear one. Additionally, cognitive,

\footnotetext{
From the Department of Cardiovascular and Thoracic Surgery, WVU Heart and Vascular Institute, West Virginia University, Morgantown, WVa.

Disclosures: The authors reported no conflicts of interest.

The Journal policy requires editors and reviewers to disclose conflicts of interest and to decline handling or reviewing manuscripts for which they may have a conflict of interest. The editors and reviewers of this article have no conflicts of interest.

Received for publication Nov 12, 2021; revisions received Nov 12, 2021; accepted for publication Nov 17, 2021; available ahead of print Nov 20, 2021.

Address for reprints: J. W. Awori Hayanga, MD, MPH, MHL, FACS, FRCS, FCCP, Department of Cardiovascular and Thoracic Surgery, West Virginia University, 1 Medical Center Drive, Morgantown, WV 26506 (E-mail: jeremiah.hayanga@ wvumedicine.org).

J Thorac Cardiovasc Surg 2022;164:1040-1

$0022-5223 / \$ 36.00$

Copyright (c) 2021 by The American Association for Thoracic Surgery

https://doi.org/10.1016/j.jtcvs.2021.11.031
}

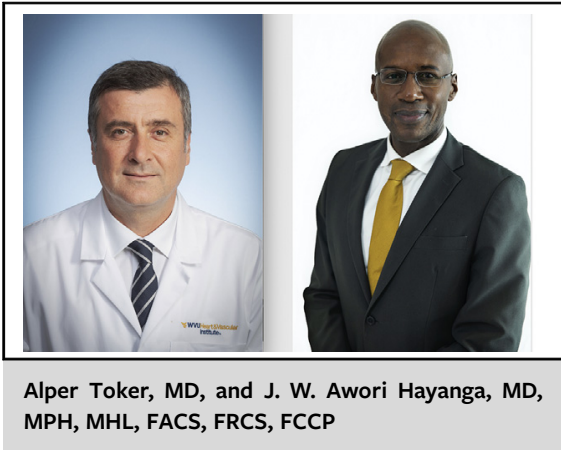

CENTRAL MESSAGE

Maintaining excellence should focus less on the adjudication of aging and more on establishing systematic protections for the patient.

and technical capabilities might wane at different rates. ${ }^{2}$ As such, one concept should not be adjudicated without permitting the other to provide contextual background.

The contributory effect of the system in the construction of a durable surgical platform cannot be underscored. The system should seek to achieve reproducible results regardless of the individual surgeon. Indeed, the measurement of individual performance is confounded by the existence of a multitude of subjective and objective factors that exert alternating partial and impartial roles that might fluctuate with time, person, or agenda. Indeed, the very complexities surrounding the accurate evaluation of performance are the same ones that complicate the adjudication of culpability when that actual performance is impaired. Indeed, in adjudicating blame, we frequently highlight the importance of establishing systematic safeguards to identify and mitigate errors, deficiencies, and lapses in the quest for excellence.

Perhaps then, in keeping with the author's aviation analogy and the spirit of retrospection and introspection, we might view performance as a function of more than just the capability of the individual surgeon. Instead, might we perhaps share the resources, scrutiny, and expectations with the system as a whole and establish a shared stakeholder alliance that makes each one accountable to the another and, of course, ultimately to the patient. As has often been expressed, a patient will suffer a bad surgeon in a great system far better than the converse. For example, 
the aviation industry has invested heavily in establishing built-in systems to protect air travel safety. Perhaps, in this vein, the quest for establishing and maintaining excellence should focus less on the adjudication of individual effects of aging in the surgeon and instead on proffering systematic protections for the patient against them.

\section{References}

1. Rosengart TK. Assessing clinical competency: the long and the short of it. $J$ Thorac Cardiovasc Surg. 2022;164:1035-7.

2. Saver JL. Best practices in assessing aging physicians for professional competency. JAMA. 2020;323:127-9. https://doi.org/10.1001/jama.2019.20249

3. Katlic MR, Coleman J, Russell MM. Assessing the performance of aging surgeons. JAMA. 2019;321:449-50. https://doi.org/10.1001/jama.2018.22216 